\title{
Poe, Cortázar e um contraponto: Machado de Assis. Ressalvas sobre uma (possível) teoria do conto.
}

Eduardo Melo França

O poeta, crítico e contista Edgar Allan Poe, na segunda resenha que escreveu sobre o Twice-told tales, de Nathanael Hawthorne, declara sua preferência pelo conto e desenvolve uma espécie de teoria sobre esse gênero. Diz ele que:

\begin{abstract}
Se nos pedissem para designar a classe de composição que, ao lado do poema, pudesse melhor satisfazer as exigências de grande genialidade, que pudesse oferecer a esta o mais vantajoso campo para o seu exercício, deveríamos falar sem hesitação do conto em prosa, como o senhor Hawthorne tem aqui demonstrado. Referimo-nos à narrativa em prosa curta, que exige de meia hora até uma ou duas horas de leitura atenta. O romance comum tem suas objeções, devido à sua extensão, pelos motivos já citados em destaque. Como não pode ser lido numa assentada, perde, é claro, a imensa força derivada da totalidade. Os interesses do mundo que intervêm durante as pausas da leitura modificam, desviam, anulam, em maior ou menor grau, as impressões do livro. Porém, a simples detenção da leitura por si só seria suficiente para destruir a verdadeira unidade. No conto breve, no entanto, o autor pode levar a cabo a totalidade de sua intenção, seja ela qual for. Durante a hora de leitura, a alma do leitor está nas mãos do escritor. Não há influências externas ou extrínsecas, produzidas pelo cansaço ou pela interrupção ${ }^{1}$ (POE, 1987, p. 47).
\end{abstract}

Norman Friedman, por sua vez, propõe uma outra solução menos teorizada e rigorosa, mais maleável e que sinceramente preferimos. Nas suas palavras, "o senso comum nos diz que, embora as fronteiras exatas não possam - e não precisam - ser determinadas, podemos muito bem distinguir, sem considerar casos extraordinários, entre ficção longa, curta e média"2 (FRIEDMAN, 1976, p. 131). Segundo Nádia Batella Gotlib, Tchekhov acreditava que a expansão da imprensa durante o século XIX possivelmente foi um dos principais estímulos para a grande produção de contos na época. Os autores, precisando de dinheiro, produziam muito e depressa (2006, p. 44). O que ela não comenta, mas podemos imaginar, é que a necessidade de ganhar dinheiro também colaborou para que os escritores se esforçassem em adequar o tamanho do conto ao formato do jornal. Mário de Andrade, numa frase de efeito tipicamente modernista, mas não muito esclarecedora, afirmou que "em verdade, sempre será conto aquilo que seu autor batizou com o nome de conto" (1972, p. 5). Massaud Moisés, como resposta, disse que "[...] a narrativa passível de ampliar-se ou adaptar-se a esquema diverso daquele em que foi concebida, não pode ser classificada de conto, ainda que o seu autor a considere, impropriamente, como tal" (1967, p. 99).

Não negamos a relevância de uma problematização acerca da intencionalidade do autor em relação à extensão do conto. Entretanto, antes disso, é fundamental que sejamos capazes de estabelecer uma clara distinção entre romance, conto e novela, que não seja apenas baseada na sua extensão ou intenção do autor, mas, quem sabe, no que podemos considerar como sendo suas diferentes possibilidades de análise do homem e 
da vida. Desse ponto de vista, o romance seria um olhar individual que busca ou atribui um sentido à totalidade da vida e da existência. A novela, também partindo de um olhar individualizado, analisa, a partir de um período de existência, suas implicações psicológicas ou sociológicas. Já o conto seria uma leitura singular (psicológica, sociológica, etc.) sobre apenas um episódio ou uma sucessão de recortes muito pequenos. No decorrer deste ensaio mostraremos que esse olhar contista também pode ser lançado não apenas sobre episódios, mas também sobre um tema, uma sensação ou simplesmente uma perspectiva de mundo. Enquanto isso, o imprescindível é atentarmos para o fato de que seja sobre um episódio ou uma reflexão, a complexidade e intensidade de um conto derivam justamente do autor precisar aproveitar todos os mínimos detalhes possíveis do seu texto para que ele se torne denso o suficiente e não apenas um relato banal de um caso qualquer.

$\mathrm{Na}$ relação leitor-romance-autor, tanto o leitor quanto o autor, cada um ao seu modo, interage, constrói e atribui ao romance um sentido particular. $\mathrm{O}$ romancista perde o domínio completo da sua obra e passa a ocupar um lugar de espectador, que ansiosamente deseja saber como suas palavras ecoam no leitor. O romance, do mesmo modo que é escrito aos pouco, paulatinamente, tendo a cada página escrita seu sentido reconstruído, ampliado, reduzido e fixado, também ao ser tomado pelo leitor, a cada frase, página e capítulo, se permite ser reconstruído, reampliado, (re)reduzido e provisoriamente fixado. No corpo do romance, entre suas frases e pausas, repousa uma imensidão de possibilidades interpretativas e efeitos, que nem o seu próprio autor tem consciência de existirem e nem o leitor conseguirá perceber totalmente. A expectativa que um romancista tem do efeito que seu texto pode gerar no leitor é sempre incerta, aberta e imprevisível.

Enquanto isso, o contista parece nunca perder o controle do conto. Por seu caráter necessariamente forte, impetuoso, tenso e palpitante, o próprio conto se apropria e consome o leitor. O conto - como diz Poe e ressalta Cortázar em Poe: O Poeta, O Narrador e O Crítico - nasce de um projeto do autor de causar um determinado efeito preconcebido (1993a, p. 121). A combinação de incidentes e palavras não é construída aos poucos como no romance, onde mesmo o autor pode, como acontece na maioria das vezes, se surpreender com a sua própria construção. Ao contrário disso, no conto, tudo é milimetricamente pensado. Cada elemento, incidente, palavra, deixa ou pausa, faz parte de um projeto que, parodiando Pablo Picasso, visa agarrar o leitor pelo rabo. ${ }^{3}$

Apesar de não o afirmarem, Poe e Cortázar parecem acreditar que apenas o conto é pensado e escrito milimetricamente, o que nos parece um certo reducionismo ou uma tentativa forçada de criar uma teoria específica para cada detalhe do conto. Afinal, como imaginar que autores de romances como Ulisses, Grande Sertão: Veredas, Enquanto Agonizo, Macunaima e Memórias Póstumas de Brás Cubas não pensaram exaustivamente em cada palavra ou idéia escolhida?

O conto, para Poe, é uma máquina literária de criar interesse. Para que essa máquina engrene, funcione perfeitamente e, principalmente, intensamente, deve se abster de tudo o que é supérfluo e desnecessário. Poe e Cortázar consideram que um conto memorável, para não dizer bom, deve se ater com intensidade a um acontecimento, suprimindo qualquer comentário ou explicação sobre o evento narrado (CORTÁZAR, 1993a, p. 122). A sua eficácia estaria intimamente ligada à sua economia e a alguns aspectos que, tal como 
muito pertinentemente compara Cortázar em "Do Conto Breve e seus Arredores", também estariam relacionados ao jazz, tais como a tensão, o ritmo, a pulsação interna, o imprevisto dentro de parâmetros pré-vistos e "essa liberdade fatal que não admite alteração sem uma perda irreparável" (1993c, p. 235). Portanto, o papel discreto, econômico e objetivo desempenhado pelo narrador seria um fator fundamental para que o conto contemporâneo, que nasce com Edgar Allan Poe, de fato seja uma máquina literária de causar efeito.

Pois bem, Poe defende que cada palavra deve estar a serviço do acontecimento em si, o que implicaria nunca fazer da matéria do conto uma alegoria, teoria, generalização psicológica ou didática. Sua essencialidade deveria ser limitada ao evento em si. Se o romance em todos os sentidos é uma obra aberta e o seu fim, dependendo de cada leitor, pode nunca existir ou se existir ir além de suas páginas, o conto, para Poe e Cortázar, é antes de tudo delimitado; atentem que não digo limitado. Sua narrativa, ao se situar no "plano essencial e, portanto, efetivo", mantém, deste modo, fora do seu alcance a possibilidade de tecer "uma visão universal do homem, até uma teleologia e uma ética" (CORTÁZAR, 1993a, p. 123 n.4).

Essa perspectiva poe-cortazeana se mostra excessivamente enrijecida e nem de longe consegue contemplar, por exemplo, alguns contos machadianos. Por isso que desde já começam nossas diferenças com esses dois críticos e contistas. Concordamos em parte, ou ao menos não discordamos completamente, com a hipótese de que a extensão de um romance pode favorecer sua maior profundidade psicológica, em comparação a um conto. No entanto, isso não deve ser encarado como uma regra, tal como praticamente fizeram Poe e Cortázar.

Apesar de Machado de Assis não ter escrito um texto crítico ou teórico sobre as principais características do conto ou quais parâmetros um autor deve supostamente seguir para que seja bem sucedido, tomaremos alguns traços gerais de seus contos não somente como contraponto para as idéias de Cortázar e Poe, mas também e especialmente como uma espécie de teoria viva sobre o gênero conto. Ou seja, a tríade aqui problematizada - Poe, Cortázar e Machado - terá nesse último autor, não argumentos em forma de discurso crítico sobre o gênero, mas de fato uma exposição prática das infinitas possibilidades - quando se trata do conto machadiano, pelo menos - de abordar um assunto na forma de conto.

Os contos de Machado, por exemplo, apesar de obviamente não serem tão extensos, principalmente os de seu período maduro, como um romance de Dostoievski, apresentam, sem a menor sombra de dúvida, o mesmo grau de profundidade, problematização e "visão universal do homem". Isso é possível em sua obra, pois, diferente do que acontece na de Poe, a essência de seus contos, se assim podemos chamar, reside na análise da densidade psicológica de seus personagens e suas motivações, não necessariamente no efeito obtido através da descrição impactante do evento em si.

O conto machadiano, e agora nos permitimos com segurança fazer uma afirmação diametralmente oposta ao que pensa Poe, é construído em função e em torno da análise da capacidade psicológica de cada personagem, que por sua vez tomará o acontecimento apenas como mote demonstrativo dessa psicologia. O acontecimento no conto machadiano está a serviço do personagem e de sua análise psicológica. Exemplo disso é "O Machete", que atende a praticamente quase todos os requisitos apontados por Poe sobre como um 
conto deve ser construído. A diferença fundamental entre o que propõe Poe e o que observamos nesse conto é o modo como ele apresenta as possibilidades de análise psicológica. O que também, por sua vez, não quer dizer que ele só funcione se concebido como uma alegoria, como supõe Cortázar.

Apesar de "O Machete" ser um conto sucinto e levar o leitor sem desvios para um caminho supostamente preconcebido pelo autor, ele não apresenta, como exige Poe, um clímax. Mesmo no seu final, quando a esposa do violoncelista Inácio Ramos foge com o tocador de machete, não há uma sensação de clímax. Essa ausência se dá pela profunda melancolia que paira nas palavras e na reflexão que o personagem faz sobre sua perda. O último momento do conto, marcado pela fuga da esposa, acaba deixando de ter um impacto de clímax, pois é obscurecido pelas palavras reflexivas e melancólicas do marido abandonado, que se sobrepõem. Será essa melancolia o primeiro passo para uma reflexão tão profunda quanto a que poderia nos oferecer um romance que também se propõe a problematizar a existência do personagem e questões importantes sobre os dilemas de um artista. Apesar de apresentar uma confluência de elementos que nos levam ao seu desfecho sem maiores rodeios, "O Machete" não nos proporciona um efeito catártico ou impactante, mas, pelo contrário, reflexivo, melancólico e silencioso.

Mesmo se fôssemos generosos com a cartilha teórica de Poe e permanecêssemos lendo "O Machete" buscando nele os traços exigidos pelo crítico e contista americano, ainda assim notaríamos que Machado desconstrói, na prática, essa suposta incompatibilidade entre análise psicológica, teorização do mundo, e clímax. Ou seja, em um só texto ele não somente encontra a solução de algo com o qual Poe não concorda, como também já demonstra como fazê-lo.

Ora, concluímos, portanto, diferentemente de Poe e Cortázar, que a presença do clímax não necessariamente está somente atrelada à idéia de que todos os elementos estão concatenados e trabalhando em função da concisão, intensidade e do seu efeito preconcebido. Em alguns casos, como em "O Machete", todos esses elementos podem estar concatenados visando não um clímax, no sentido proposto por Poe, mas, sim, uma reflexão final.

Ainda tomando algumas estórias de Machado como ao mesmo tempo teoria-viva do conto e uma espécie de prova-teste para as idéias de Poe e Cortázar, lancemos vista sobre o conto "Idéias de Canário", que além de apresentar uma estrutura que parece se mover em função de uma teorização, ainda assim cria no leitor, como tanto pede Poe, uma expectativa acerca do desfecho da ação que move o conto.

Partindo de "Idéias de Canário" nossas discordâncias com os dois teóricos tornamse ainda mais agudas. Nele, se há um certo clímax final, esse poderia ser melhor definido como uma Grand reflexão finale pessimista sobre a relatividade e a impossibilidade de estabelecermos uma verdade definitiva sobre a liberdade. Qualquer alteração no modo de contar essa estória implicaria numa desarrumação desse pensamento e, por conseqüência, não causaria no leitor a sensação de coerência e convencimento que ela nos transmite acerca da relatividade da liberdade. Todos os elementos do conto estão arranjados de uma forma tal que ao seu fim possamos visualizar a construção de uma espécie de teoria (pessimista) sobre o relativismo da liberdade. 
Tomando emprestadas as palavras que Luís Augusto Fisher (2008, p. 28) utilizou para definir a ficção de Kafka, diríamos que não raras vezes, e isso é estridente em "Idéias de Canário", Machado escreve ficção simulando a voz de um ensaio. Nem todo conto é construído em função de um efeito arrebatador. Alguns são, como em vários de Machado, especificamente em função de uma teorização ou problematização de aspectos do mundo e da existência. Um leitor mais atento perceberá que por trás do Machado contista há um outro personagem tão impetuoso que não se contém e sempre se faz ser notado: o Machado pensador. Em todos os seus contos suspira um raciocínio que vai além do acontecimento em si, da análise psicológica, da estória e dos personagens, resvalando numa racionalização, problematização e finalmente teorização do mundo.

Talvez, seja por decorrência da necessidade do leitor, quando diante do conto machadiano, não apenas entender a trama de sua estória, mas também compreender as idéias que dele nascem e se ramificam, que surja a sensação ingrata, mas ao mesmo tempo deliciosa e instigante, de acharmos que estamos sempre perdendo alguma coisa do texto, como se o autor estivesse falando algo que não conseguimos entender ou perceber. Machado escreve não somente bons contos e estórias, ele faz uma literatura de idéias. Ao lado de Tchekhov, Kafka, Guimarães Rosa, Dostoievski, Proust, Henry James e alguns outros autores, ele ocupa um lugar na tênue linha que divide o escritor ficcionista do pensador humano que não concebe outra possibilidade a não ser a de em tudo o que escreve entranhar a sua concepção de homem e mundo.

O estranhamento causado entre um olhar mais atento sobre "Idéias de Canário" e as palavras de Poe e Cortázar pode ser ainda mais revelador. Revelador, pois, desta vez, Machado parece utilizar toda a parafernália exigida por Poe, e contrariando Cortázar, consegue proporcionar ao leitor justamente o que ambos os críticos negam como parte de um conto, isto é, "uma visão universal do homem, até uma teleologia e uma ética". Ao que parece, Poe não conseguiria encaixar exatamente "Idéias de Canário" em algum esquema, pois, além dele criar no leitor uma expectativa específica acerca do que acontecerá com o canário no transcorrer de suas mudanças de habitat, mudanças essas retratadas em seqüência de quadros, também lhe possibilita uma reflexão final sobre o mundo. Machado concilia a necessidade da ação e do suspense com a da reflexão. Concilia o sensível com o inteligível.

Segundo Cortázar, cada conto começa por interessar a inteligência, mas termina se apoderando da alma do leitor (1993a, p. 125). Também já falamos que não concordamos com a idéia de que o clímax seja parte fundamental de um conto ou que ele exclua a possibilidade reflexiva. Essa exigência pode nos permitir imaginar que se o conto começa como uma máquina literária de criar interesses, ao fim se torna uma espécie de máquina literária de causar sensações, o que não necessariamente acontece nos contos de Machado, pelo menos não no sentido das palavras de Poe. Mesmo os contos machadianos que não consideramos como sendo os mais profundos e devastadores, ainda assim são mais cerebrais do que emocionais. E se boa parte deles pode ser considerada memorável, excelente e irretocável, isso se dá muito mais pelo efeito desnorteante e problematizador de suas reflexões e teorias implícitas sobre o homem, do que por qualquer efeito impactante ou catártico que um clímax possa causar no leitor. 
Sabemos que quando Poe e Cortázar falam de clímax, eles estão se referindo a algo que nos lembra a idéia de catarse, isto é, uma fruição de sensações. Em linguagem mais simples, espanto, susto, surpresa, revelação impactante, etc. Cabe, porém, nos questionarmos até que ponto a revelação ou sugestão de uma problematização ou teorização da vida e do mundo também não pode gerar no leitor, principalmente no mais reflexivo, não somente um clímax (poeano), mas algo maior, tal como uma sensação de efeito desnorteante e desorganizador.

Não creditamos, sinceramente, que haja alguma epifania, catarse, clímax ou surpresa que possa causar no leitor um efeito necessariamente muito mais intenso do que o pessimismo arrebatador que ecoa de "Idéias de Canário" ou do que a melancolia devastadora que exala d"'O Machete". Enfim, sabemos exatamente o que Poe e Cortázar querem dizer com clímax e por isso não nos arriscaremos a dizer que podemos encontrálo, tal como o propõem, nesses dois contos de Machado. Entretanto, mais do que esse clímax, podemos ser mais exigentes e esperar de um conto algo muito maior, mais devastador e conceitualmente mais largo, que é um efeito desnorteante, desorganizador e reposicionador diante do mundo.

Poe, nas palavras de Cortázar, "compreendeu que a eficiência de um conto depende de sua intensidade como acontecimento puro, isto é, que todo comentário ao acontecimento em si [...] deve ser radicalmente suprimido" (1993a, p. 122). Talvez essa ênfase no acontecimento em si seja por sua teoria do conto ter como base, principalmente, os contos fantásticos. No caso de Machado, é fácil encontrarmos entre seus contos alguns que possam ser classificados tipicamente como fantásticos. Contudo, em Machado, o fantástico, o assustador e o que (aparentemente) beira o extra-humano e nos causa esse efeito de estranhamento são justamente os contos que denunciam as patologias mentais e comportamentos insólitos que menos desejaríamos admitir que nós, seres humanos, somos capazes de realizar.

O próprio Freud, no ensaio "O Estranho" de 1919, tomou emprestado o conto fantástico "Homem de Areia", de E.T.A. Hoffman, para demonstrar que muito do efeito desconcertante que algumas pessoas, situações, objetos, histórias ou estórias aparentemente estranhas nos causam, é por conta de eles nos remeterem a aspectos que inconscientemente nos são familiares, mas conscientemente não. Tomando emprestada essa idéia de Freud, poderíamos dizer que contos como "Um Esqueleto" e "A Causa Secreta" geram esse sentimento de estranhamento, desconforto, aparente macabro e fantástico, pois evidenciam algo que está distante de nós, mas, atentemos, não distante no sentido externo e sim interno. Para Freud, nem tudo que nos é aparentemente estranho ou desconhecido está no mundo "exterior". Alguns dos nossos aspectos psicológicos podem

Sabemos que quando Poe e Cortázar falam de clímax, eles estão se referindo a algo que nos lembra a idéia de catarse, isto é, uma fruição de sensações. Em linguagem mais simples, espanto, susto, surpresa, revelação impactante, etc. Cabe, porém, nos questionarmos até que ponto a revelação ou sugestão de uma problematização ou teorização da vida e do mundo também não pode gerar no leitor, principalmente no mais reflexivo, não somente um clímax (poeano), mas algo maior, tal como uma sensação de efeito desnorteante e desorganizador. 
Não creditamos, sinceramente, que haja alguma epifania, catarse, clímax ou surpresa que possa causar no leitor um efeito necessariamente muito mais intenso do que o pessimismo arrebatador que ecoa de "Idéias de Canário" ou do que a melancolia devastadora que exala d"'O Machete". Enfim, sabemos exatamente o que Poe e Cortázar querem dizer com clímax e por isso não nos arriscaremos a dizer que podemos encontrálo, tal como o propõem, nesses dois contos de Machado. Entretanto, mais do que esse clímax, podemos ser mais exigentes e esperar de um conto algo muito maior, mais devastador e conceitualmente mais largo, que é um efeito desnorteante, desorganizador e reposicionador diante do mundo.

Poe, nas palavras de Cortázar, "compreendeu que a eficiência de um conto depende de sua intensidade como acontecimento puro, isto é, que todo comentário ao acontecimento em si [...] deve ser radicalmente suprimido" (1993a, p. 122). Talvez essa ênfase no acontecimento em si seja por sua teoria do conto ter como base, principalmente, os contos fantásticos. No caso de Machado, é fácil encontrarmos entre seus contos alguns que possam ser classificados tipicamente como fantásticos. Contudo, em Machado, o fantástico, o assustador e o que (aparentemente) beira o extra-humano e nos causa esse efeito de estranhamento são justamente os contos que denunciam as patologias mentais e comportamentos insólitos que menos desejaríamos admitir que nós, seres humanos, somos capazes de realizar.

O próprio Freud, no ensaio "O Estranho" de 1919, tomou emprestado o conto fantástico "Homem de Areia", de E.T.A. Hoffman, para demonstrar que muito do efeito desconcertante que algumas pessoas, situações, objetos, histórias ou estórias aparentemente estranhas nos causam, é por conta de eles nos remeterem a aspectos que inconscientemente nos são familiares, mas conscientemente não. Tomando emprestada essa idéia de Freud, poderíamos dizer que contos como "Um Esqueleto" e "A Causa Secreta" geram esse sentimento de estranhamento, desconforto, aparente macabro e fantástico, pois evidenciam algo que está distante de nós, mas, atentemos, não distante no sentido externo e sim interno. Para Freud, nem tudo que nos é aparentemente estranho ou desconhecido está no mundo "exterior". Alguns dos nossos aspectos psicológicos podem nos parecer sombrios, assustadores e desconhecidos por estarem nas camadas mais profundas, distantes e inconscientes de nossa mente.

Essa pequena digressão psicanalítica não é gratuita. Ela é importante para a construção do nosso argumento. Parece que sem muito esforço podemos admitir que mesmo em Hoffman, um autor fantástico e tão caro a Poe, é absolutamente plausível, pois assim fez Freud, encontrar ou a partir dele construir uma visão sobre o comportamento humano. Isto é, não só em Machado, um contista notoriamente psicológico e teorizador, mas também em Hoffman, um notoriamente fantástico, encontramos material que desmente a exigência feita por Poe de construir o conto em torno apenas do "evento em si" e a de Cortázar de excluir "uma visão universal do homem".

Admitamos que não somente no conto, mas também no romance, o autor, em determinados momentos, tanto adequa a forma do texto a suas idéias quanto suas idéias à forma que pretende finalmente construir. Cortázar diz que o conto é antes de tudo delimitado, que sua narrativa deve se situar no "plano essencial e, portanto, efetivo", mantendo, por conseguinte, fora do seu alcance a possibilidade de tecer "uma visão 
universal do homem, até uma teleologia e uma ética". Tomemos alguns exemplos para verificar essa concepção poeana do conto como sendo um gênero limitado, em relação ao romance, do ponto de vista da problematização e da análise psicológica.

Ora, como entender, num primeiro momento, diante dessa teoria, um conto que não foi concebido a princípio como conto, mas como um capítulo de romance e que apenas posteriormente fora excluído pelo autor do formato final de sua obra, como, por exemplo, o conto "Mrs. Dalloway na Bond Street" de Virginia Woolf? Sobre essa abordagem, digamos genética, desse conto de Virginia Woolf, seu tradutor para o português, em nota de rodapé, escreve que: "Publicado na revista The Dial, em 1923, este conto inicialmente foi escrito como primeiro capítulo de Mrs. Dalloway" (WOOLF, 1984, p.181).

Ainda tomando "Mrs. Dalloway na Bond Street" como exemplo, como Poe justificaria necessariamente a maior profundidade de um romance diante de um conto, se no caso do romance Mrs. Dalloway seu tradutor afirma que sua origem na verdade é a reunião, evidentemente reacomodada, de sete contos originalmente publicados separadamente no mesmo The Dial (WOOLF, 1984, p.181)? ? Se, para Poe e Cortázar, apenas um romance é capaz de problematizar uma visão universal do homem, como entender que essa profundidade teorizadora tem origem em sete contos originalmente independentes? Por último, como explicar, ou ainda justificar, os capítulos de romances que funcionam perfeitamente como contos, tais como "História de D. Plácida" ou "O Almocreve" das Memórias Póstumas de Brás Cubas?

Vale repensar se o capítulo que foi a princípio concebido como parte de um romance, ao se fixar como conto, perderia de fato todas as marcas que indicam, por exemplo, a densidade psicológica do personagem ou generalizações sobre o resgate do tempo e da memória, como no caso de "Mrs. Dalloway na Bond Street". Nessa mesma trilha, vale questionar até que ponto é plausível acreditar que os sete contos formadores de Mrs. Dalloway passam a apresentar a existência de uma temática que vai além do acontecimento em si somente quando estão reunidos em forma de romance. Por fim, no caso dos capítulos que funcionam como contos, como entender que no meio de um romance haveria um recorte - um capítulo - que estivesse destituído das intenções e (amplas e profundas) possibilidades de um romance e apenas funcionasse pontualmente como uma narrativa de um evento em si? Seria possível negar que, além de ter uma estrutura e função semelhante à de um conto, o capítulo "O Almocreve" também possibilita uma reflexão que vai além da descrição intensa do episódio e problematiza o cinismo e o egoísmo humano?

Concordamos em gênero, número e grau quando Boris Schnaiderman diz que a escrita de Tchekhov é uma superação em relação ao que propõe Poe em sua "Filosofia da Composição" (1999, p. 334). Isto porque foi exatamente Tchekhov quem pela primeira vez apresentou de forma incisiva o conto como sendo algo a mais do que o relato de um acontecimento. $\mathrm{O}$ escritor russo foi o responsável por libertar definitivamente o conto de um dos seus fundamentos mais marcantes: a narrativa de um acontecimento extraordinário (GOTLIB, 2006, p. 46). Semelhante ao que também ocorre em muitos contos de Machado, em alguns de Tchekhov há a impressão de nada significativo acontecer. As narrativas aparentemente não possuem enredo e relatam estórias comuns que, segundo os mandamentos de Poe, não mereceriam ser tomadas como matérias de conto. Em 
Tchekhov, isso acontece, por exemplo, em "Angústia" e "Dois Amigos". Em Machado, em "Missa do Galo" e "Teoria do Medalhão".

É preciso que se entenda que não há evento extraordinário ou acontecimento em si que seja digno de ser matéria de conto, romance, poema ou qualquer outro gênero literário. Como disse Balzac em Modesta Mignon, "A maioria dos dramas está nas idéias que formamos das coisas. Os acontecimentos que nos parecem dramáticos são apenas assuntos que a nossa alma converte em tragédia ou em comédia, à mercê do nosso caráter”. Henry James também reforça essa idéia dizendo que:

[...] a experiência nunca é limitada e nunca é completa; ela é uma imensa sensibilidade, uma espécie de vasta teia de aranha, da mais fina seda, suspensa no quarto de nossa consciência, apanhando qualquer partícula do ar em seu tecido. É a própria atmosfera da mente; e quando a mente é imaginativa - muito mais quando acontece de ela ser a mente de um gênio - ela leva para si mesma os mais tênues vestígios de vida, ela converte as próprias pulsações do ar em revelações (JAMES, 1995, p. 29).

H. James, sem dúvida, está ao lado de escritores como Machado e Tchekhov, que consideram a necessidade da experiência em si como obsoleta, superficial e quase inútil para o trabalho artístico. A realidade, um quadro, um evento, uma situação ou um simples relance carecem sempre de interpretação, de impressão. Carecem do "poder de adivinhar o não-visto do visto, de traçar implicação das coisas, de julgar toda a peça pelo padrão, a condição de sentir a vida em geral tão completamente que você se sente disposto a conhecer cada canto dela" (JAMES, 1995, p. 30). E se Poe faz tanta questão do acontecimento em si, James, em outras palavras, lhe responderia enfaticamente dizendo que a experiência consiste simplesmente em impressões (1995, p. 31).

Todorov percebeu que boa parte dos contos de Poe encerra com uma "frase derradeira, carregada de maior significação, que ao mesmo tempo esclarece sabiamente o mistério mantido e anuncia um fato, em geral horrível” (1980, p. 162). Diferente disso, nos contos mais psicológicos escritos por Machado e Tchekhov, além da profundidade psicológica dos personagens, uma das coisas que mais chama a atenção é um silêncio final perturbador ou uma certa pulsação enigmática que permanece no leitor mesmo após terminar de lê-los. Nesses, ao contrário do que acontece nos de Poe - e na maioria dos policiais ou de terror - não há necessariamente algum enigma a ser desvendado, problema a ser solucionado ou revelação a vir à tona. Ao invés de neles encontrarmos desfechos com soluções ou conclusões do tipo da anagnórise, na qual todo o restante da trama seja reconhecido e esclarecido, encontramos estórias ambíguas que mantêm questões sutis em aberto e a serem solucionadas pelo próprio leitor a partir das mais diversas interpretações.

Essa possibilidade do conto manter-se em aberto com questões não solucionadas e sem respostas definitivas para sua trama está em "Missa do Galo". Nesse conto, o próprio narrador diz: "Nunca pude entender a conversação que tive com uma senhora, há muitos anos, contava eu dezessete, ela trinta" (MACHADO DE ASSIS, 1997, p. 605). Ninguém é capaz de chegar à conclusão acerca do que realmente aconteceu naquela noite, nem o narrador e muito menos o leitor. Em Missa do Galo, nem mesmo uma conclusão distorcida ou parcial nos é oferecida. Pelo contrário, apenas a ratificação de que a verdade 
sobre o episódio está perdida, restando unicamente ao leitor imaginar e analisar as intenções dos personagens e os indícios que parecem levá-lo a respostas incertas sobre as intenções de ambos. Teria Nogueira visto D. Conceição naquela noite com um "ar de visão romântica" porque lia Os Três Mosqueteiros e estava "ébrio de Dumas"? E ela, uma mulher traída e conformada, estaria envolvida naquela conversação porque desejava se sentir novamente capaz de seduzir? Apenas impressões nos restam sobre a conversa entre Nogueira e Conceição. Impressões que, segundo o próprio Nogueira, são "truncadas e confusas". Diante dos desfechos enigmáticos que os contos de Machado oferecem, somos levados a fazer milhares de perguntas. Para algumas obtemos respostas ambíguas; para outras, apenas um silêncio perturbador.

Ainda sobre os contos que não apresentam "conclusões", lembremos de "Uns Braços". Aparentemente, trata-se de uma estória simples. E de fato o é. Complexos são os personagens e os seus sentimentos: ambíguos, reprimidos, sutis, introspectivos, não declarados e indefiníveis, uma vez que não nos esclarecem nada e aparentemente não se justificam. Anteriormente falamos da concepção poeana do conto, que o define como uma narrativa delimitada e que se encerra em si mesma. Mas como então definir o sentimento de perplexidade que permanece no leitor diante do clima discreto de sensualidade e sedução que é construído em "Uns Braços"? Acreditamos não sermos os únicos que, após a leitura do conto, ainda permanecemos sentindo a sensualidade pulsante em D. Severina, ao beijar Inácio enquanto ele dorme ou ao mostrar parte dos braços de forma sedutora durante as refeições. E mais, também não acreditamos sermos os únicos compelidos, a partir dessa estória, a olhar para o mundo agora com uma lente machadiana e conseguir enxergar em tantas outras situações da vida esse mesmo jogo tácito de sedução representado na relação entre D. Severina e Inácio, na qual ambos desejam, mas enquanto um não se permite, ao outro não é permitido.

Enquanto Poe alimenta sua pretensão e intenção na possibilidade de que o acontecimento em si cause efeito e impacto no leitor, o conto machadiano se estrutura e apóia o seu objetivo mais importante, não no acontecimento, mas na capacidade de interpretá-lo e atribuir-lhe sentido. Mesmo Cortázar, que em vários momentos parece concordar com Poe, disse, no ensaio "Alguns Aspectos do Conto", que, ao ler A Lição de Mestre, de Henry James, reconheceu que alguns acontecimentos em si carecem de significado. Para ele, nesse livro de Henry James "sente-se de imediato que os fatos em si carecem de importância, que tudo está nas forças que os desencadearam, na malha sutil que os precedeu e os acompanha" (CORTÁZAR, 1993b, p. 158). "Interpretar as interpretações", disse Montaigne, "dá mais trabalho do que interpretar a própria coisa, mas escrevemos mais livros sobre livros do que sobre os assuntos mesmos; comentamonos uns aos outros" (MONTAIGNE, 1987, p. 352).

O próprio James, se interpretarmos suas palavras apropriadamente, parece também não admitir essa dissociação entre acontecimento e sentido, experiência e impressão - e em última instância - entre significante e significado. Diz ele que a "história ${ }^{5}$ e o romance, a idéia e a forma, são a agulha e o fio, e nunca ouvi falar de alfaiate que recomendem o uso do fio sem a agulha, ou da agulha sem o fio" (JAMES, 1995, p. 40).

A Lição de Mestre reúne três aspectos interessantes que tocam, problematizam e, mais do que tudo, nos possibilitam mais uma vez desfazer o esquema excessivamente 
rígido e excludente proposto pela teoria poe-cortazeana. Primeiro: diferentemente do que diz Cortázar (1993b, p. 158), essa peça não é uma narrativa demorada. Indiscutivelmente trata-se de uma estória curta e pode ser lida rapidamente, e de uma só vez. Se A Lição de Mestre, de Henry James, não é exatamente um conto curto, definitivamente não é um romance e pode facilmente ser lido em apenas algumas horas, como exige Poe. Tanto a etiqueta de um conto mais longo, quanto a de uma novela curta cabem bem a esta peça. Nesse sentido, ela atende aos mandamentos poe-cortazeanos.

Segundo: notemos que a narrativa parece seguir o mesmo ritmo da matéria narrada. Ou seja, ela é lenta, cadenciada, compassada e gradual, exatamente como um dos passeios que ocorrem na casa de campo onde o jovem escritor Paul Overt, a encantadora Srta. Fancourt e o admirado Henry St. George estão hospedados. A Lição de Mestre, exatamente como é narrado, seria uma perfeita matéria de conversação em algum desses aparentemente agradáveis passeios feitos pelos seus personagens. Sua matéria, e a forma como é contada, caberia exatamente na boca de qualquer um de seus personagens aristocráticos ou intelectualizados. Além de ser uma narrativa "caudalosa", como diz Cortázar, esse ritmo lento e cadenciado certamente não faz crescer no leitor expectativa alguma em relação a qualquer final surpreendente ou impactante, ainda mais após a longa conversa que Paul trava com St. George sobre vida e arte. Conversa essa, vale salientar, que muito nos lembra a que encontramos em “Teoria do Medalhão". Lembra na forma, evidentemente, e não no teor, que são diametralmente opostos. Ambos os autores, com essas conversas, transformam, durante algumas páginas, o conto quase em uma explanação teórica. Em Lição de Mestre, uma explanação acerca da relação que um escritor deve manter com a vida. Na "Teoria do Medalhão", sobre como um indivíduo que deseja ser aceito pela sociedade deve se portar.

Essa narrativa, que parece mais flutuar lentamente do que zunir de forma direcionada e certeira, como quer Poe, nos faz crer que a estória terá como desfecho alguma teorização ou problematização acerca do amor ou da arte. Entretanto, inesperadamente, o anúncio do casamento entre a Srta. Fancourt e o recém viúvo Henry St. George surge como um tapa na cara do leitor. Um susto. Algo inesperado e com o qual não sabemos lidar e principalmente justificar. Daí, novamente, ressaltarmos que nesse longo conto as ações e o real em si não se justificam, mais importando o que não vemos e o que os personagens sentem.

Se, por um lado, o anúncio do casamento não chega a provocar uma explosão de sensações, podemos dizer que ele representa um certo clímax na trama, surpreendentemente constrangedor se lembramos do jantar no qual Paul encara St. George pela última vez. Esse clímax, porém, para ainda mais contrariar a rigidez excludente das idéias de Poe e Cortázar, parece vir acompanhado nas últimas linhas do conto por uma brevíssima reflexão final acerca do inesperado comportamento de St. George e da conclusão a que Paul chega sobre seu caráter e a conversa que com ele tivera em seu escritório.

Um aspecto fundamental: se num primeiro momento o anúncio (e, por que não?, também o último jantar) cumpre a função e o lugar do clímax, numa segunda leitura o que mais nos intriga é saber se essa inquietude causada no leitor é fruto do anúncio em si ou da interrogação e indefinição acerca das motivações de St. George e Srta. Fancourt. 
Temos, portanto, para bagunçar de vez a teoria de Poe, um clímax gerado justamente por uma dúvida acerca das motivações de uma atitude e de um acontecimento que em si carece de densidade e justificativa aparente!

O terceiro ponto, que já foi citado e ainda não nomeado, funciona como uma costura entre os outros dois, uma vez que se trata da não excepcionalidade dos acontecimentos da estória. O mais importante e o que mais pulsa nesta pequena novela é a necessidade de interpretação dos atos e sentimentos dos personagens e das dúvidas que permanecem em aberto. Sobre a necessidade de uma aventura ou um acontecimento extraordinário para se fazer ficção, Henry James (1995 p. 41) propõe, ironizando, ao invés de aventuras, por que não uma ficção baseada em um par de óculos verdes? Enfim, temos em $A$ Lição do Mestre ao mesmo tempo quase tudo o que Poe e Cortázar pregam e negam, mas articulados de forma orgânica, como que de fato em uma lição de mestre. Justapondo a obra crítica e ficcional de Poe, encontramos coerência entre seus preceitos e sua prática literária, o que não acontece com Cortázar, que quase injustificadamente endossa o pensamento de Poe sobre o conto, mas na prática escreve estórias evidentemente não condicionadas ao tal acontecimento em si.

É importante questionarmos qual a necessidade do acontecimento em si para a construção de um conto ou como podemos encontrá-lo na vida. Podemos até admitir que a vida é roteirizada por acontecimentos, visíveis ou sentidos, mais estridentes ou silenciosos. No entanto, melhor a compreenderá e mais intensamente a viverá quem for capaz de revesti-la de sentidos e significados. O Real, tão inatingível como chama e define Lacan, não vem acompanhado por carimbo explicativo. Cabe ao escritor, seja contista, poeta ou romancista, transformar este tal Real, esse acontecimento em si, em realidade, imbuindo-o de significados onde aparentemente são injustificados e sugerindo dúvidas e aberturas onde superficialmente são indubitáveis e auto-explicativos.

A esta altura já deve ser evidente que situamos Henry James ao lado de Machado e o contrapomos a Poe e Cortázar, tomando sua obra também como uma teoria viva sobre literatura. Em A Lição de Mestre, é possível pinçar momentos teóricos sobre o que é arte e sua relação com o mundo. O artista, como diz St. George, deve ter a capacidade de transformar as coisas em ouro (JAMES, 1996, p. 88). E aqui completamos por nossa conta: ele deve ter um toque de Midas literário. Não deve esperar os acontecimentos pertinentes à literatura surgirem na sua frente, mas transformá-los em matéria literária, ser capaz de tomar os assuntos, acontecimentos, sensações ou pensamentos mais banais e comuns e neles encontrar a humanidade necessária para então estetizá-los. Não existem temas ou acontecimentos dignos e pertinentes para a literatura. Se Midas não procurava o ouro, mas transformava nisso tudo o que tocava, o escritor com sua sensibilidade é que deve, não descobrir a literatura no mundo, mas transformar o mundo em literatura; não descobrir a poesia nos acontecimentos, mas dar aos acontecimentos poesia.

Outra significativa marca deixada por Tchekhov que vai de encontro a tudo o que pensa Poe é a possibilidade do conto não necessariamente narrar um recorte único da vida do personagem, mas "registrar uma sucessão de quadros, como se fosse um mosaico, abandonando a construção tradicional, que previa uma ação com desenvolvimento, clímax e desenlace" (GOTLIB, 2006, p. 47). Nessa fórmula, o contista recortaria apenas acontecimentos significativos da vida do personagem, o que ocorre em 
vários contos de Machado. Em "O Esqueleto", o narrador constrói uma seqüência de acontecimentos ou passagens capazes de denunciar o desejo de Dr. Belém de causar medo e temor à esposa. Em "A Causa Secreta", são encadeados seguidos quadros que retratam o sadismo de Fortunato. Em "D. Benedita", o narrador não se preocupa em descrever toda a vida da personagem ou da sociedade ao seu redor, mas apenas concatena uma seqüência de quadros que ressalta a incapacidade da personagem levar a cabo qualquer atividade. Em cada um desses contos há como que uma espécie de coletânea dos melhores, mais significativos e representativos momentos da vida dos personagens. A união desses recortes deve ser suficiente para que tenhamos uma noção da totalidade da psicologia de cada um deles. Esse mosaico constitui o que Brás Cubas chamou de "substância da vida".

Escrever um conto, assim como um poema ou romance, implica intenções e (algumas) técnicas específicas. Não é isso que negamos. O que questionamos é até que ponto cada um desses gêneros guarda a capacidade de retratar de forma específica e essencial apenas algumas condições humanas. Há algo que só um romance pode dizer, sentimentos que somente um poema pode transmitir e sensações que apenas um conto pode causar?

Vejamos, por exemplo, o sumário e injustificadamente notório Decálogo do Perfeito Contista de Horácio Quiroga. Desafio qualquer escritor ou crítico a apontar algum desses mandamentos como sendo absolutamente intrínseco e exclusivo à arte de escrever contos. Todos os dez itens apontados por Quiroga podem e devem ser adotados por qualquer um que deseja simplesmente escrever literatura. Vejamos apenas alguns:

(I) Crê num mestre - Poe, Maupassant, Kipling, Tchekhov - como na própria divindade. (V) Não começa a escrever sem saber, desde a primeira palavra, aonde vais. Num conto bemfeito, as três primeiras linhas têm quase a mesma importância das três últimas.

(VII) Não adjetiva sem necessidade, pois são inúteis as rendas coloridas que venhas a pendurar num substantivo débil. Se dizes o que é preciso, o substantivo, sozinho, terá uma cor incomparável. Mas é preciso achá-lo.

Qual autor não tem em Tchekhov um mestre? Saber de onde começamos e para onde iremos não seria uma estratégia que imaginamos ter sido também adotada por um Guimarães Rosa ao escrever o Grande Sertão: Veredas ou por Euclides da Cunha em Os Sertões? E João Cabral de Melo Neto, subtraindo ao máximo de seus poemas o adjetivo teria utilizado uma regra essencial apenas à construção de contos?

Mesmo Cortazar, que teoricamente parece seguir obedientemente os mandamentos de Poe, positivamente nos surpreende e em certo momento diz que "[...] ninguém pode pretender que só se devam escrever contos após serem conhecidas suas leis. Em primeiro lugar não há tais leis; no máximo cabe falar de pontos de vista, de certas constantes que dão uma estrutura a esse gênero tão pouco classificável" (1993, p. 150). Assim como H. James, em $A$ Lição de Mestre, considerou equivocado o Sr. Besant tentar dizer tão definitivamente no que consiste um bom romance, também consideramos que mais do que qualquer teorização enrijecida sobre o conto, o maior pecado de Poe, e o de Cortázar em apoiá-lo, é tentar definir no que consiste especificamente e milimetricamente um bom conto. Seja um conto, romance, poesia ou crônica, a única obrigação e regra que a literatura deve seguir é a de ser interessante! (JAMES, 1995 p. 26) 
Apesar de todos os contrapontos que estabelecemos em relação às idéias de Poe, não estaríamos sendo contraditórios se admitíssemos que inegavelmente um conto, entre tantas características e controvérsias, de fato, essencialmente se estrutura como um texto curto. Nas palavras de Friedman, "[...] um conto pode ser curto, para começar com uma distinção básica, por uma ou ambas de duas razões fundamentais: a matéria em si pode ser de pequeno compasso; ou a matéria, sendo de uma esfera maior, pode ser cortada de forma a maximizar o efeito artístico"7 (1976, p. 133). Sobre a relação entre a extensão do conto e sua intensidade, encontramos na correspondência de Tchekhov um alerta que ele faz a um escritor iniciante. Ao seu aprendiz, diz ele que "suas obras carecem da compactação que tornam vivas as coisas curtas” (THEKHOV, 1974, p. 23).

Cortázar é feliz quando compara o trabalho do contista com o de um fotógrafo. Em ambos, é preciso ter noção de que o recorte a ser trabalhado precisa aproveitar todos os detalhes, uma vez que são sucintos e intensos. O escritor deve enxergar, tanto na matéria curta em si quanto na que foi concentrada intensamente num relato breve, a mesma possibilidade e dimensões artísticas e problematizadoras que um fotógrafo ao definir seu alvo e foco. Tanto o conto quanto a fotografia devem ser densos, intensos e breves, pois, quando memoráveis, retratam recortes representativos da vida ou amostras concentradas da psicologia humana. Nas palavras de Cortázar, tanto a fotografia quanto o conto consistem em " [...] recortar um fragmento de realidade, fixando-lhe determinados limites, mas de tal modo que esse recorte atue como uma explosão que abre de par em par uma realidade muito mais ampla [...]" (1993b, p. 151).

Apesar de consideramos coerente a comparação entre a fotografia e o conto, não podemos deixar de reparar que se agora Cortázar diz que o conto pode proporcionar uma "realidade mais ampla", anteriormente ele também afirmou que o conto deveria se limitar ao "plano essencial e, portanto, efetivo" (1993, p. 123), o que implica manter fora do seu alcance a possibilidade de tecer "uma visão universal do homem, até uma teleologia e uma ética” (CORTÁZAR 1993a, p. 123. n.4). Uma contradição. Ficaria assim a questão: Cortázar acredita na possibilidade do conto ser mais do que uma narrativa do acontecimento em si?

Essa psicologização, teorização ou problematização do mundo e das pessoas que emerge do conto machadiano, por exemplo, parece ser resumida por James como um "propósito moral consciente", isto é, uma certa voz que lateja em todo aquele conto que não admite a restrição ao evento em si e se permite ser tão amplo e profundo quanto um romance ou poema. E, pela última vez pegando carona nas reflexões de James, cabe ao crítico não dogmático se perguntar se esse "propósito moral consciente" pode ser classificado na obra machadiana como simplesmente o registro de um fato ou, bem mais do que isso, se ele funciona como uma espécie de princípio estabelecido, uma vez que, como sabemos, é constante em quase todos os seus contos e pode ser considerado uma marca registrada de sua obra, forma e pensamento.

Para além do conto ou da discussão do gênero literário, é necessário ampliar o conceito e pensarmos, como diz Henry James, na arte da ficção. Arte esta que, quando exercida por Machado, Tchekhov e o próprio James, apresenta o que ele próprio exige em seu ensaio homônimo: uma autoconsciência, uma expressão não somente de um credo artístico, mas - e aqui completamos nós - principalmente humano. 
Notas

1 "Were we called upon however to designate that class of composition which, next to such a poem as we have suggested, should best fulfill the demands of high genius — should offer it the most advantageous field of exertion - we should unhesitatingly speak of the prose tale, as Mr. Hawthorne has here exemplified it. We allude to the short prose narrative, requiring from a half-hour to one or two hours in its perusal. The ordinary novel is objectionable, from its length, for reasons already stated in substance. As it cannot be read at one sitting, it deprives itself, of course, of the immense force derivable from totality. Worldly interests intervening during the pauses of perusal, modify, annul, or counteract, in a greater or less degree, the impressions of the book. But simple cessation in reading would, of itself, be sufficient to destroy the true unity. In the brief tale, however, the author is enabled to carry out the fullness of his intention, be it what it may. During the hour of perusal the soul of the reader is at the writer's control. There are no external or extrinsic influences — resulting from weariness or interruption"

2 "Common sense tells us that, although the exact dividing lines cannot — and need not — be determined, we can pretty well distinguish, apart from marginal cases, between long, short, and medium fiction."

${ }^{3}$ O Desejo pelo Rabo. Peça de Pablo Picasso escrita em 1941, mas censurada e apenas encenada pela primeira vez 26 anos depois.

${ }^{4}$ Todos esses sete contos em suas versões originais podem ser encontrados no livro de contos Uma casa Assombrada de Virginia Woolf.

${ }^{5} \mathrm{O}$ acontecimento, a aventura.

${ }^{6}$ Os sentidos e significados atribuídos pelo autor.

7 "A story may be short, to begin with a basic distinction, for either or both of two fundamental reasons: the material itself may be of small compass; or the material, being of broader scope, may be cut for the sake of maximizing the artistic effect..."

\section{Bibliografia}

ANDRADE, M. de. O empalhador de passarinho. São Paulo: Martins; Brasília: INL, 1972.

CORTÁZAR, J. Poe: o poeta, o narrador e o crítico. In: Valise de cronópio. Trad. Davi Arrigucci Jr. e João Alexandre Barbosa. São Paulo: Perspectiva, 1993a. p. 103-146.

. Alguns aspectos do conto. In: Valise de Cronópio. 1993b. p. 147-163.

. Do conto breve e seus arredores. In: Valise de Cronópio., 1993c. p. 227-237.

FREUD, S. O estranho (1919). In: Edição Standard Brasileira das Obras Psicológicas Completas, v.17. Rio de Janeiro: Imago, 1976.

FISCHER, L. A. Machado e Borges, clássico e formativos. In: Machado e Borges - e outros ensaios sobre Machado de Assis. Porto Alegre: Arquipélago Editorial, 2008.

FRIEDMAN, N. What Makes a Short Story Short? In: MAY, C. E. (Ed.). Short Story Theories. Athens: Ohio University Press, 1976. p. 131-146

GOTLIB, N. B. Teoria do conto. 11ª . São Paulo. Ed. Ática, 2006.

JAMES, H. A Arte da ficção. Trad. Daniel Piza. São Paulo: Ed. Imaginário, 1995. . A lição de mestre. Trad. Afonso Teixeira Filho e Rui Costa Pinto. Rio de Janeiro: Paz e Terra, 1996.

MACHADO DE ASSIS, J. M. Obras completas, vol 2. Rio de Janeiro: Ed. Nova Aguilar, 1997.

MONTAIGNE, M. E. de. Da Experiência. In: Ensaios v. 3. Trad. Sérgio Milliet. Brasília: Ed. Hucitec. Editora Universidade de Brasília, 1987.

MOISÉS, M. A criação literária. São Paulo: Melhoramentos, 1967.

POE, E. A. Review of Twice-Told Tales. In: MAY, Charles E. (edited by). Short Story Theories. Ohio: Ohio University Press, $1987.6^{\circ}$ ed. p.45-51.

. The Philosophy of Composition. In: MC. MICHAEL, George L. Concise Anthology of American literature. $2^{\circ}$ ed. New York: MacMillan Publishing Company. 1985, $2^{\circ}$ Ed. P. 431-439. 
SCHNAIDERMAN, B. Pósfacio. In: TCHEKHOV, A. P. A dama do cachorrinho e outros contos. São Paulo: Ed. 34, 1999.

TCHEKHOV, A. P. On Problems of Technique in the Short, Story. In: CURRENT- GARCIA, EUGENE \& PATRICK, WALTON, R. (Eds.). What Is the Short Story? Glenview; Brighton: Scott, Foresman, 1974, p. 20-29.

TODOROV, T. Os gêneros do discurso. Trad. Elisa Angotti Kossovitch. São Paulo: Martins Fontes, 1980.

WOOLF, V. Uma casa assombrada. Trad. José Antônio Arantes. Rio de Janeiro: Nova Fronteira, 1984. 